\title{
Pregnancy-Induced Hypertension is Accompanied by Decreased Number of Circulating Endothelial Cells and Circulating Endothelial Progenitor Cells
}

\author{
Jerzy Heimrath · Maria Paprocka • Andrzej Czekanski • \\ Agata Ledwozyw $\cdot$ Aneta Kantor $\cdot$ Danuta Dus
}

Received: 11 July 2013/ Accepted: 11 December 2013/Published online: 23 February 2014

(C) The Author(s) 2014. This article is published with open access at Springerlink.com

\begin{abstract}
Maternal endothelial dysfunction is one of the main features of pregnancy-induced hypertension (PIH). It is generally accepted that circulating endothelial cells (CECs) and endothelial progenitor cells (EPCs) reflect the state of the endothelium, its injury and/or repair possibilities. The objective of this study was to determine whether the CECs and EPCs numbers in the circulation of women with PIH reflect the presence of this pathology. Peripheral blood cells of PIH and normotensive pregnant women were labeled with specific monoclonal antibodies. For CECs evaluation, samples were labeled with anti-CD31 and antiCD45 antibodies; for EPCs with anti-VEGFR2/KDR and anti-CD34 antibodies. Cells were quantified by flow cytometry. The levels of both CECs $\left(\mathrm{CD} 31^{+}, \mathrm{CD} 45^{-}\right)$and EPCs $\left(\mathrm{CD} 34^{+}, \mathrm{VEGFR} 2 / \mathrm{KDR}^{+}\right)$in the peripheral blood of women with $\mathrm{PIH}$ were significantly lower compared with those of control pregnant women with normal blood pressure level. Lowered accessibility of maternal CECs and EPCs may diminish general regenerative potential of the patient endothelia, contributing to PIH symptoms and to the risk of subsequent coronary and arterial disease.
\end{abstract}

Keywords CECs $\cdot$ EPCs $\cdot$ Preeclampsia

J. Heimrath

Department of Gynaecology and Obstetrics, Faculty of Health

Science, Wrocław Medical University, Wrocław, Poland

M. Paprocka ( $₫)$ - A. Ledwozyw - A. Kantor · D. Dus Ludwik Hirszfeld Institute of Immunology and Experimental Therapy, Polish Academy of Sciences, Rudolfa Weigla 12,

53-114 Wrocław, Poland

e-mail: paprocka@iitd.pan.wroc.pl

A. Czekanski

Second Department and Clinic of Gynaecology, Obstetrics and Neonatology, Wrocław Medical University, Wrocław, Poland

\begin{abstract}
Abbreviations
CECs Circulating endothelial cells

EPCs Endothelial progenitor cells

PIH Pregnancy-induced hypertension
\end{abstract}

\section{Introduction}

According to current opinion, arterial pregnancy-induced hypertension (PIH) is caused by insufficient placental flow. In PIH trofoblast fails to modulate its phenotype, which results in impaired, shallow invasion of spiral arteries. Reduced uteroplacental perfusion induces series of hypoxia/ischemia events, accompanied with the imbalance between vasodilative and the vasopressive factors, a dysfunction of the renin-angiotensin system as well as endothelium activation. This activation is not restricted to placental vessels but affects also other maternal endothelia, making PIH a multisystemic disease. Preeclampsia is a pregnancy pathology in which PIH is accompanied by proteinuria and associated with an increased risk of subsequent coronary and arterial diseases (Blum et al. 2003; Gilbert et al. 2008; Harskamp and Zeeman 2007; Kaufmann et al. 2003; Robb et al. 2007; Zhang et al. 1997).

Dysfunction of vascular endothelium in PIH women is accompanied by elevated amounts of syncytiotrophoblast particles and increased levels of several soluble adhesion molecules, e.g., sVCAM and sICAM, in peripheral blood (Heimrath et al. 2004). Other studies have shown that concentration of serum vascular endothelial growth factor (VEGF), von Willebrand factor and fibronectin was also elevated. Levels of soluble markers, tumor necrosis factor, endothelin and angiotensin II, may also be elevated whereas the vasodilator levels, nitric oxide and prostacyclin levels, are usually diminished (Blum et al. 2003; 
Gammill et al. 2007; Gilbert et al. 2008; Hunter et al. 2000; Kwon et al. 2007).

Circulating endothelial cells (CECs) and endothelial progenitor cells (EPCs) reflect the state of the endothelium, its injury and/or repair possibilities (Hunting et al. 2005). CECs are cells peeled off from the vessel wall during normal or pathological conditions, such as acute inflammation or mechanical trauma. CECs are usually defined as cells expressing endothelial cell markers, such as CD146, CD31 or Willebrand factor, but negative for CD45 (Blann et al. 2005; Khan et al. 2005; Mancuso et al. 2001; Monestiroli et al. 2001; Woywodt et al. 2002).

Several studies have demonstrated that EPC may participate in the postnatal neoangiogenesis. These cells are characterized by expression of such markers as CD133, CD34 and VEGFR2 (VEGF receptor 2, also known as KDR) (Hristov and Weber 2004; Hunting et al. 2005; Robb et al. 2007; Timmermans et al. 2009).

The aim of this study was to determine whether the CECs and EPCs numbers in the PIH patients may reflect the presence of this pathology.

\section{Materials and Methods}

\section{Subjects}

The study involved 18 pregnant women, 21-35 years, with PIH, defined according the criteria of blood pressure elevation $\geq 140 / 90 \mathrm{mmHg}$, measured at least twice, $6 \mathrm{~h}$ apart, after 20th week of gestation in a previously normotensive women. Dopegyt (Methyldopa) and Dihydralzine were applied as a standard antihypertension treatment. Preeclampsia was diagnosed in six women (30\%) with PIH, on the basis of the presence of $300 \mathrm{mg}$ of protein or more in a 24-h urine sample. In the group studied, ten women $(55.5 \%)$ were primigravida and eight women $(44.5 \%)$ were multipara. Seven of them $(38.8 \%)$ had premature labor (before the end of the 37th week of pregnancy). The control consisted of 21 pregnant women aged 22-43 years, with normal blood pressure level, having natural labor in term; and included 10 (47.5\%) primigravida and $11(52.5 \%)$ multipara. All women had monovular pregnancies. Main clinical characteristics of both patient groups were gathered in a Table 1. Pregnant women in both groups were carefully selected. There was no patient with HELLP syndrome (preeclampsia variant, characterized by hemolysis, elevated liver enzymes and low platelet count). Patients with overweight, cigarette smoking, diabetes or hypertension were not included in the group. The main difference between control and PIH groups was average delivery time: 40 vs. 37 weeks, respectively, as in PIH pregnancy usually there is a need
Table 1 Characteristics of study groups

\begin{tabular}{lll}
\hline & Control & PIH patients \\
\hline Number of patients & 21 & 18 \\
Age & $28( \pm 5)$ & $30( \pm 9)$ \\
Blood pressure (mm Hg) & $122( \pm 10)$ & $174( \pm 15)$ \\
Systolic & $79( \pm 12)$ & $110( \pm 15)$ \\
Diastolic & $0 / 21$ & $6 / 18$ \\
Proteinuria & $40( \pm 2)$ & $37( \pm 4)$ \\
Gestational age at the & & \\
blood sampling (week) & $21 / 21$ & $2 / 18$ \\
Natural birth & $0 / 21$ & $16 / 18$ \\
Cesarean section & $3,433.6( \pm 400)$ & $2,934.6( \pm 500)$ \\
Infantile birth weight $(\mathrm{g})$ & $47.5 \%$ & $55.5 \%$ \\
Rate of primipara &
\end{tabular}

of a delivery before the term because of complications related to hypertension.

The material examined was venous blood drawn directly before birth into test tubes with an anticoagulant. The Bioethics Commission of the Wroclaw Medical University approved this study and all patients gave informed consent.

Flow Cytometry Analysis of CECs and EPCs Numbers in Peripheral Blood

To determine CECs number, blood samples of PIH patients and normotensive pregnant women were labeled with FITC-conjugated anti-CD31 and PerCP-conjugated antiCD45 antibodies (BD Biosciences, USA). To evaluate EPCs number PerCP-conjugated anti-CD34 (BD Biosciences, USA) and PE-conjugated anti-VEGFR2/KDR antibodies (R\&D Systems, USA) were used. Blood samples were incubated first with FcR-blocking reagent (Miltenyi Biotec, Germany) and then with selected antibodies. Isotype matched, labeled immunoglobulins (BD Biosciences, USA or R\&D Systems, USA, respectively) were used as a control. After incubation Lysing Solution (Sigma, Germany) was applied to eliminate erythrocytes and fluorescent CytoCount beads (Dako, Denmark) were used for cell number evaluation. Minimal numbers of 150,000 cells were collected. Flow cytometry was performed using FACSCalibur cytometer, CellQuest software (Becton-Dickinson, USA) and appropriate cell gating to eliminate platelets and dead cells (debris gate). EPCs were evaluated from lymphocyte gate (Redondo et al. 2008) and CECs from mononuclear cells gate (Mancuso et al. 2001; Monestiroli et al. 2001; Redondo et al. 2008). Data were expressed as a cell count per $1 \mathrm{~mL}$ of blood. Cell numbers obtained by flow analysis for control normotensive group and PIH patients were compared using Mann-Whitney 
$U$ test (Statistica 6.0 software). Differences were considered as statistically significant when $p<0.05$.

\section{Results and Discussion}

As the endothelium dysfunction plays a significant causal role in PIH, we have decided for evaluation, in the same patients, both EPCs and CECs to receive more complete insight into the problem. Pregnant women with PIH were found to have approximately twice lower counts of both EPCs and CECs as compared to normotensive healthy controls. An average EPCs number in peripheral blood of healthy controls was $2.48 \times 10^{2}$ but in PIH patients it decreased to $1.03 \times 10^{2}$ per $1 \mathrm{~mL}$ ( $p=0.000001$; Fig. 1$)$. CECs counts were $2.77 \times 10^{3}$ in healthy controls and $1.28 \times 10^{3}$ per $1 \mathrm{~mL}$ in PIH patients ( $p=0.0034$; Fig. 2 ). Obtained differences were statistically significant.

The process of neoangiogenesis means in situ proliferation of local endothelial cells but involves also EPCs mobilized from bone marrow (Hristov and Weber 2004). To pass over a lack of specific marker for EPC, two, three or even more markers have to be applied to discriminate these from platelets and lymphocytes (Robb et al. 2007; Timmermans et al. 2009).

Our data confirm a few published data that EPCs level in PIH women was diminished. Sugawara et al. (2005)

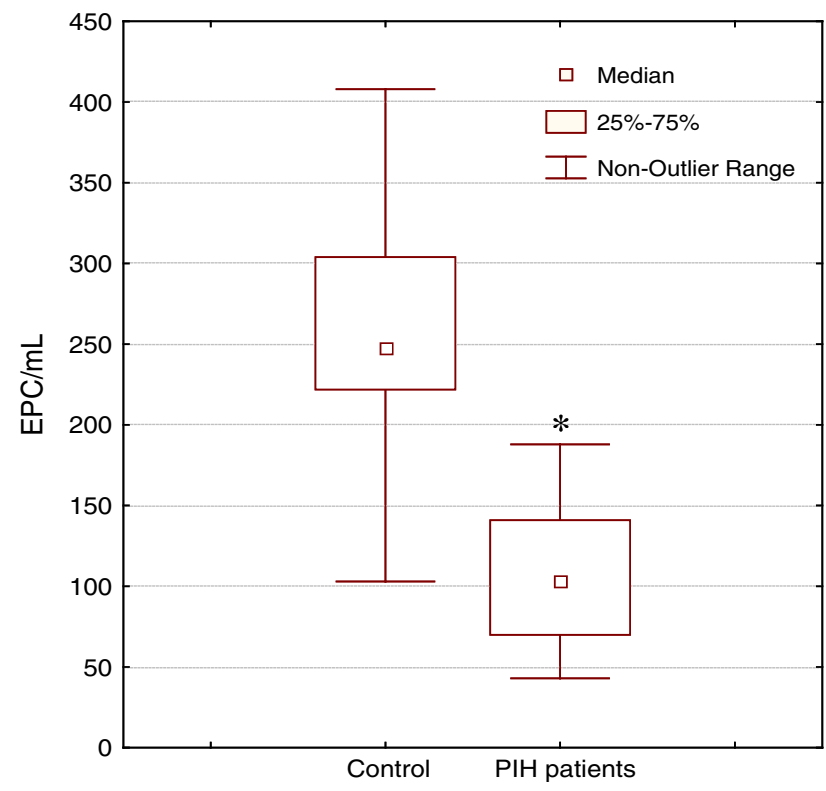

Fig. 1 The numbers of endothelial progenitor cells (EPCs) in $1 \mathrm{~mL}$ of blood of normotensive pregnant woman and patients with pregnancy-induced hypertension (PIH) evaluated by flow cytometry. Significantly decreased cell numbers were observed in PIH patients: $1.03 \times 10^{2}$ when compared with normal pregnant control: $2.48 \times 10^{2}$ per $1 \mathrm{~mL}(* p=0.000001)$

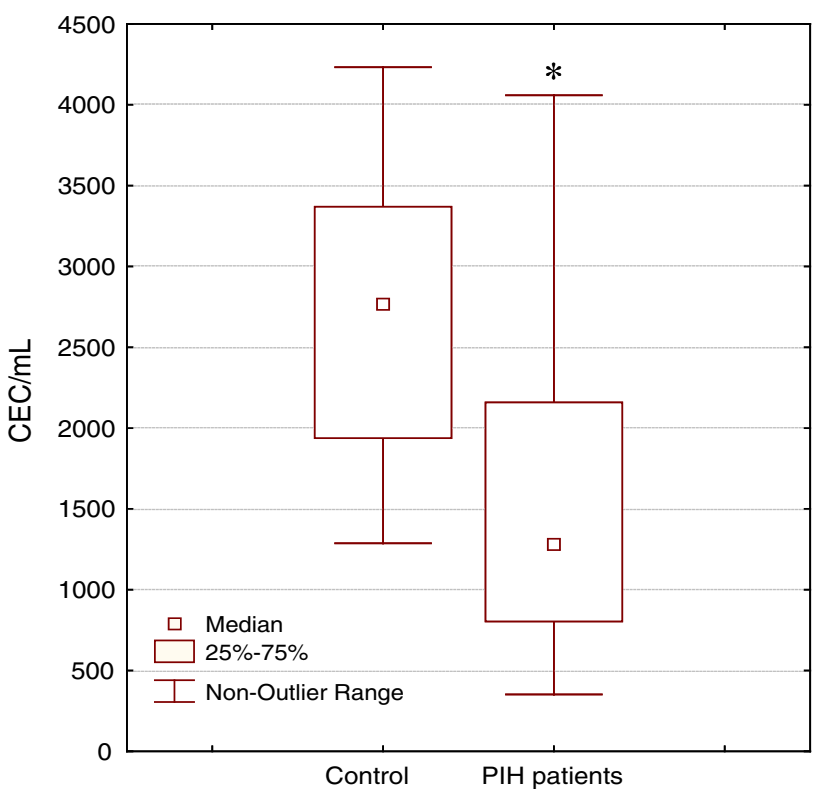

Fig. 2 The numbers of circulating endothelial cells (CECs) in $1 \mathrm{~mL}$ of blood of normotensive pregnant woman and patients with pregnancy-induced hypertension $(\mathrm{PIH})$ evaluated by flow cytometry. Significantly decreased cell numbers were observed in PIH patients: $1.28 \times 10^{3}$ when compared with normal pregnant control: $2.77 \times 10^{3}$ per $1 \mathrm{~mL}(* p=0.0034)$

reported decrease in EPCs number and found EPCs cellular senescence. Kwon et al. (2007) also found decreased number of EPCs in preeclampsia. Gammill et al. (2007) have reported that EPCs number increases in healthy pregnancy but similar increase was not observed in woman with preeclampsia. Only Matsubara et al. (2006) did not find significant differences in EPCs levels.

CECs number in healthy people, reported in the literature, ranges from 0 to 7,900 per $1 \mathrm{~mL}$ of blood (Khan et al. 2005; Steurer et al. 2008). Our data concerning CECs differ from those from other laboratories. We have found lower counts of CECs in PIH patients, compared to normotensive controls, while publications by Zheng et al. (1996) and Grundmann et al. (2008) reported augmented number of CECs in PIH patients. However, their CECs enumerating methods were different. Zeng's group isolated CECs before their counting under microscope, and Grundmann's group separated CECs with anti-CD146 antibody and stained cells with Ulex lectin, which may result in enumeration of different cell subpopulations. All ten patients evaluated by Grundman's study were patients with preeclampsia. PIH and preeclampsia patients were presented together in our study, as we had not found any difference in CECs number in these groups.

It seems also possible that some of CECs released from activated endothelium disintegrate and form microparticles (EMs), small vesicles of endothelial cell membrane, containing cytoplasm. In preeclampsia EMs levels, evaluated 
by flow cytometry as $\mathrm{CD} 62^{+}$and $\mathrm{CD} 31^{+} \mathrm{CD} 45^{-}$microparticles, were significantly higher than in healthy controls (Gonzalez-Quintero et al. 2004). In our study microparticles were not specifically labeled nor evaluated but by gating living cells for CEC and EPC counting, we could observe augmented debris number in PIH patients (data not shown). This suggests excessive cell's damage which may influence final CECs count.

Because EPCs and CECs levels in the peripheral blood of women with PIH were found to be significantly lower as compared with those of normotensive pregnant women we suggest that this phenomenon often accompanied the pathology. Patients selected for our study were without overweight, diabetes or hypertension but decreased number of EPC and CEC numbers may be associated with other pathological processes such as insulin resistance, which was also demonstrated to impair functions of these cells (Thadhani et al. 2004).

One may assume that lower accessibility of these maternal cells impairs regenerative capabilities of the endothelium and may be one of the factors contributing to the development of pregnancy-induced hypertension. In addition, general endothelial dysfunction and lowered number of cells able to restore vascular bed may give, as a remote effect, augmented risk of cardiovascular diseases, as it was demonstrated recently (Harskamp and Zeeman 2007).

Conflict of interest Authors declare no conflicts of interest relevant to the subject matter and materials discussed in the manuscript.

Open Access This article is distributed under the terms of the Creative Commons Attribution License which permits any use, distribution, and reproduction in any medium, provided the original author(s) and the source are credited.

\section{References}

Blann AD, Woywodt A, Bertolini F et al (2005) Circulating endothelial cells. Thromb Haemost 93:228-235

Blum A, Shenhav M, Baruch R et al (2003) Endothelial dysfunction in preeclampsia and eclampsia: current etiology and future non invasive assessment. Isr Med Assoc J 5:724-726

Gammill HS, Lin C, Hubel CA (2007) Endothelial progenitor cells and preeclampsia. Front Biosci 12:2383-2394

Gilbert JS, Ryan MJ, LaMarca BB et al (2008) Pathophysiology of hypertension during preeclampsia; linking placental ischemia with endothelial dysfunction. Am J Physiol Heart Circ Physiol 294:H541-H550

Gonzalez-Quintero VH, Smarkusky LP, Jimenez JJ et al (2004) Elevated plasma endothelial microparticles: preeclampsia versus gestational hypertension. Am J Obstet Gynecol 194:1418-1424

Grundmann M, Woywodt A, Kirsch T et al (2008) Circulating endothelial cells: a marker of vascular damage in patients with preeclampsia. Am J Obstet Gynecol 198(317):e1-e5
Harskamp RE, Zeeman GG (2007) Preeclampsia: at risk for remote cardiovascular disease. Am J Med Sci 334:291-295

Heimrath J, Krawczenko A, Kozlak J et al (2004) Trophoblast and soluble adhesion molecule in peripheral blood of women with pregnancy-induced hypertension. Am $\mathrm{J}$ Reprod Immunol 51:152-155

Hristov M, Weber C (2004) Endothelial progenitor cells: characterization, pathophysiology and possible clinical relevance. J Cell Mol Med 8:498-508

Hunter A, Aitkenhead M, Caldwell C et al (2000) Serum levels of vascular endothelial growth factor in preeclamptic and normotensive pregnancy. Hypertension 36:965-969

Hunting CB, Noort WA, Zwaginga JJ (2005) Circulating endothelial progenitor cells reflect the state of endothelium: vascular injury, repair and neovasculatization. Vox Sang 88:1-9

Kaufmann P, Black S, Huppertz B (2003) Endovascular trophoblast invasion: implications for the pathogenesis of intrauterine growth retardation and preeclampsia. Biol Reprod 69:1-7

Khan SS, Solomon MA, McCoy JP Jr (2005) Detection of circulating endothelial cells and endothelial progenitor cells by flow cytometry. Cytom B Clin Cytom 64:1-8

Kwon JY, Maeng YS, Kwon YG et al (2007) Decreased endothelial progenitor cells in umbilical cord blood in severe preeclampsia. Gynecol Obstet Invest 64:103-108

Mancuso P, Burlini A, Pruneri G et al (2001) Resting and activated endothelial cells are increased in the peripheral blood of cancer patients. Blood 97:3658-3661

Matsubara K, Abe E, Matsubara Y et al (2006) Circulating endothelial progenitor cells during normal pregnancy and preeclapmsia. Am J Reprod Immunol 56:79-85

Monestiroli S, Mancuso P, Burlini A et al (2001) Kinetics and viability of circulating endothelial cells as surrogate angiogenesis marker in animal model of human lymphoma. Cancer Res 61:4341-4344

Redondo S, Hristov M, Gordillo-Moscoso AA et al (2008) Highreproducible flow cytometric endothelial progenitor cell determination in human peripheral blood as CD34+/CD144+/CD3lymphocyte sub-population. J Immunol Methods 335:21-27

Robb AO, Mills NL, Newby DE et al (2007) Endothelial progenitor cells in pregnancy. Reproduction 133:1-9

Steurer M, Kern J, Zitt M et al (2008) Quantification of circulating endothelial and progenitor cells: comparison of quantitative PCR and four channel flow cytometry. BMC Res Notes 1:71

Sugawara J, Mitsui-Saito M, Hayasi C et al (2005) Decrease and senescence of endothelial progenitor cells in patient with preeclampsia. J Clin Endocrinol Metab 90:5329-5332

Thadhani R, Ecker JL, Mutter WP et al (2004) Insulin resistance and alterations in angiogenesis: additive insults that may lead to preeclampsia. Hypertension 43:988-992

Timmermans F, Plum J, Yöder MC et al (2009) Endothelial progenitor cells: identity defined? J Cell Mol Med 13:87-102

Woywodt A, Bahlmann FH, Groot K et al (2002) Circulating endothelial cells: life, death, detachment and repair of endothelial cell layer. Nephrol Dial Transplant 17:1728-1730

Zhang J, Zeisler J, Hatch MC et al (1997) Epidemiology of pregnancy-induced hypertension. Epidemiol Rev 19:218-232

Zheng Y, Chen Z, Yan J (1996) Study of the relationship between complement activation and vascular endothelial damage in pregnancy induced hypertension. Zhonghua $\mathrm{Fu}$ Chan $\mathrm{Ke} \mathrm{Za}$ Zhi 31:152-155 